\title{
Use of software solution CEIT Table in designing of an automated logistics system
}

\author{
Vsevolod Bastiuchenko ${ }^{1}$, Monika Bučková ${ }^{1}$, Radovan Furmann ${ }^{1}$ \\ ${ }_{1}$ University of Žilina, Faculty of Mechanical Engineering, Department of Industrial \\ Engineering \\ Univerzitná 8215/1, 01026 Žilina, Slovakia \\ vsevolod.bastiuchenko@fstroj.uniza.sk \\ monika.buckova@fstroj.uniza.sk \\ radovan.furmann@fstroj.uniza.sk
}

\begin{abstract}
Annotation: This article describes the basic information about automation, the questions that need to be asked when using automation in the form of AGV trucks in practice. The Ceit Table software and its use in solving the project of implementing an automated logistics system are also described. With the help of working with Ceit Table software, we described the steps of the project of implementation of an automated logistics system in the Ceit Table software environment. These descriptions are supplemented by methodologies and examples from Ceit Table software.
\end{abstract}

\section{Introduction to automation}

The effectiveness of the organization of logistics in the company depends on creating a logistics system for the company. The logistics system is one of the main elements of a company's organization. Its application allows the integration of various business processes and organizes internal processes with minimal costs, with the optimal adaptation of the company's internal environment to external factors that affect its activities. The process of forming a corporate logistics system is complex, so it is appropriate to divide it into several stages. Automation is a stage of industrial production characterized by the liberation of a person from the direct implementation of control of the production process functions and the transfer of these functions to automatic devices [7]. In ancient Greek, the meaning of "automatos" meant "automatic."

Today, almost no technical processes can be done without automation - from simple systems used in everyday life to the most complex industrial production processes [4]. In this article, we will deal with the topic of the methodology of implementation of an automated logistics system with the help of the software solution CEIT Table.

Between the tasks of automation, it is possible to include:

- increase productivity and optimize equipment loading,

- improving the quality of the product through strict adherence to technological procedures, 
- ensuring safety and improving working conditions,

- increasing the use of material, and so on.

The disadvantage is that modern equipment and software as well as highly qualified professionals are required to fulfil these tasks. In this article, we will focus on the description of the implementation of an automated logistics system using the CEIT Table software solution using methodological steps. We will also gradually describe the possibilities of using this software tool in the designing of logistics systems.

\section{Automated logistics}

One way to implement automatic transport is the AGV (Automated Guided Vehicles) system. It is not only the transport of material from point $A$ to point $B$ along a predetermined route but also a complex system consisting of tractors, dynamic conveyors or transfer stations that can deliver the material on time and unload it automatically at a specified time. The software Ceit Table can process, respond to production data and make independent decisions. Before it is possible to use a software, it is necessary to learn all the limitations and anticipate the problems that may occur in the process of designing or functioning the system. Below are important questions that we must be able to answer and make a final solution. To designing of logistics systems or visualize the use of AGV trucks in practice, it is necessary to answer several questions:

- Is the aisle width suitable?

- Are the twists satisfactory?

- Is the surface where the AGV will operate satisfactory?

- Is it possible to transport material using an AGV Low Pallet truck?

- Is the material weight suitable for AGV Low Pallet truck?

- Is there enough space in the workplace for unloading and loading material?

- Is there a place in the production, warehouse for creating of a charging station?

- Is the connection on the Wi-Fi network stable?

When the conditions for the use of technology are met, the software can be used to create a pilot project to visualise the future automated process. It is also possible to follow the steps described in the subchapter 2.2.

\subsection{Software CEIT Table}

The CEIT Table software product (Fig. 1) is an integrated solution to support the intuitive, team-oriented, virtual designing of production systems [1]. Using the right combination of software and hardware makes it possible to speed up 
and optimize the entire designing process while maintaining team decisionmaking capabilities. The CEIT Table environment contains tools to support basic activities related to designing and production layout:

- creation of optimal disposition in accordance with efficient logistics,

- capacity planning and operations of production, logistics and warehousing processes in one place,

- workplace balancing and standardization of operations,

- logistics flow planning and capacity planning of handling equipment,

- design and capacity dimensioning of warehouses,

- ergonomic design and evaluation of workplaces, and so on.

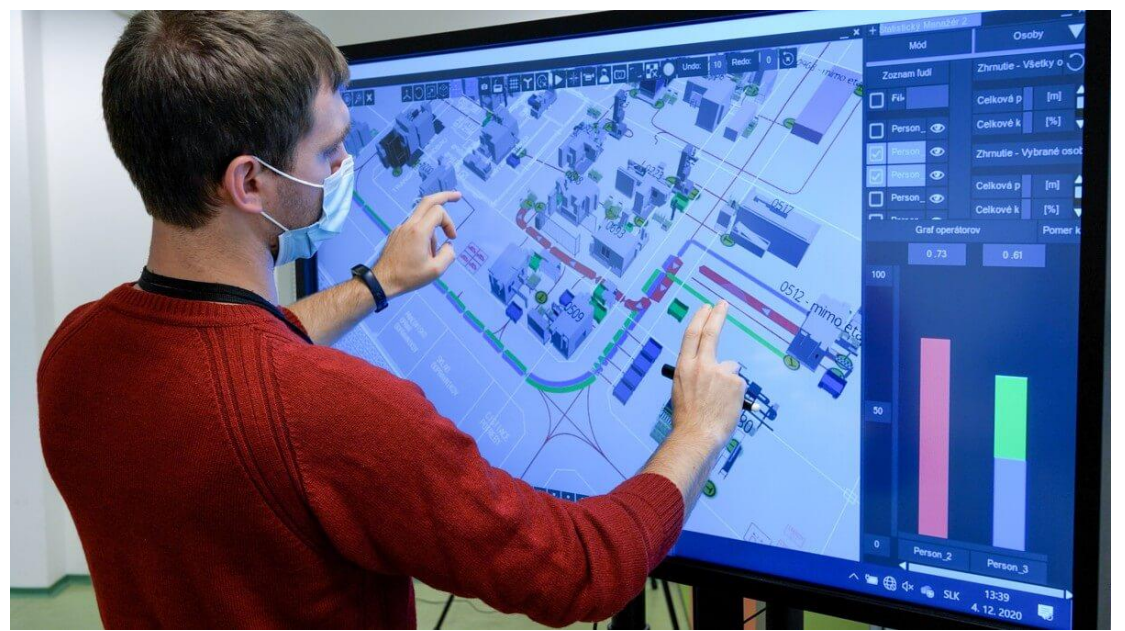

Figure 1 - Working with CEIT Table software (Source: Asseco CEIT, a. s.)

One of the main advantages is the possibility to see the future production or warehousing in a virtual reality environment before it is put into real conditions and thus identifies possible collisions. Import and export data from CEIT Table are compatible with other software such as AutoCAD, Microstation and Microsoft Excel, which allows their interconnection [1]. In Fig. 1, it is shown a workspace of software Ceit Table during the designing of the logistic system.

\subsection{Steps of the project of implementation of automated logistics system}

Perfectly implemented automation simplifies the life of companies and the production process while saving time, human resources and especially money. It is not possible to start right away by deploying the booths of the automated logistics chain itself or the overall system or by setting up a software solution. This issue is addressed at the Department of Industrial Engineering in cooperation with Asseco CEIT a. s. The steps of the project of the implementation of the automated logistics system will be described: 
1. Initial phase of the project

2. The intention of the company's management and the definition of the problem

3. Formation of the research team and analytical workshop

4. Creation of solving team

5. Schedule and division of tasks

6. Data collection

7. Process analysis

8. Summary of analysis results

9. Design creation using CEIT Table software

\section{Step 1: Initial phase of the project}

Project identification (Figure 2) is the first stage of system design. Its task is to get acquainted with the company, find out the company's intentions, determine the problem (for example, problems with the delivery of goods from the warehouse to workplaces) and solution strategy and set up a solution team.

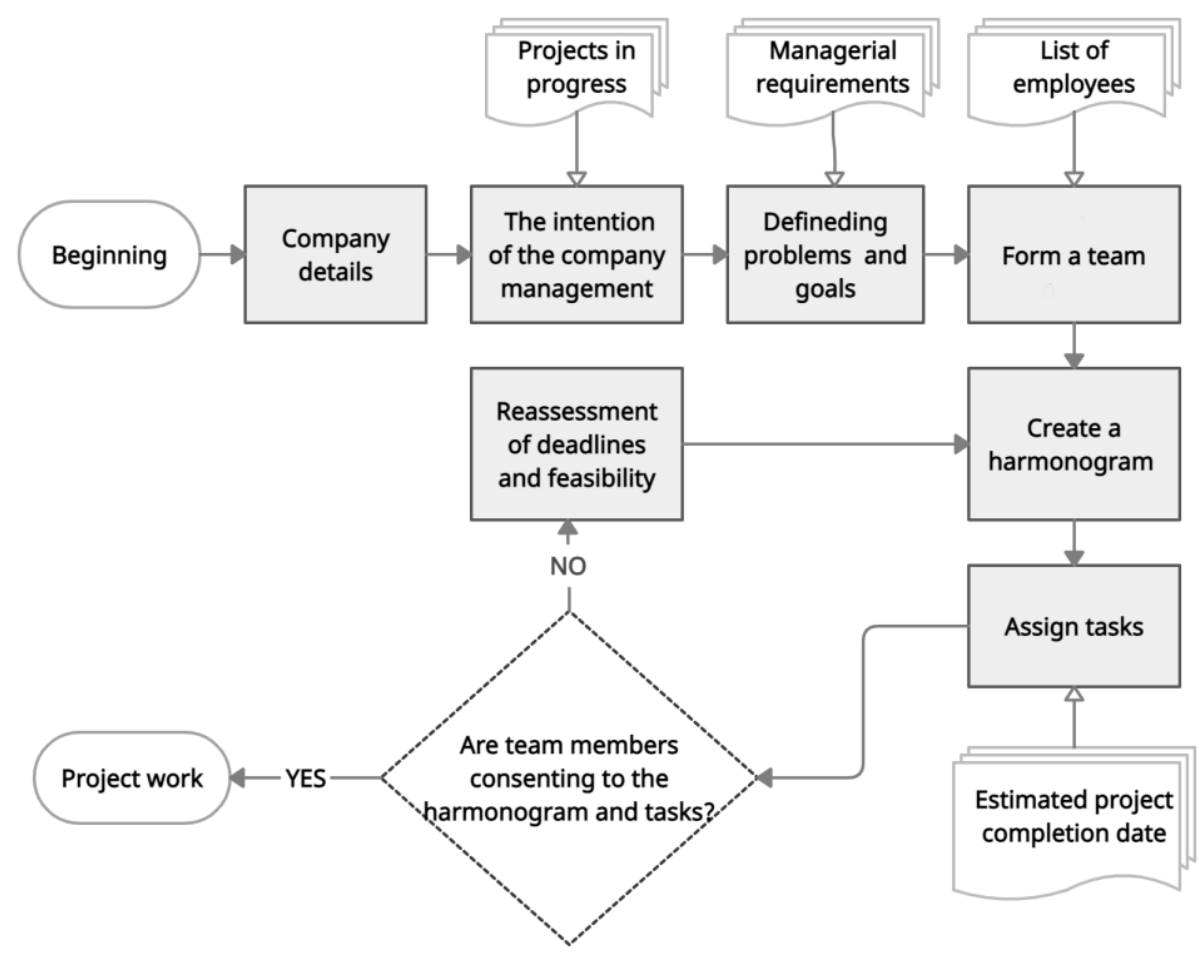

Figure 2 - Project identification algorithm (Source: Bastiuchenko, Vsevolod) 


\section{Step 2: The intention of the company's management and the definition of the problem}

The beginning of a new project is an important phase of defining the strategy for the future and the focus of the company's management. Subsequently, given the company's strategy, determine exactly how to solve the problem. This phase is necessary to avoid disagreements between team members in the future, from different company levels from the shop floor to the highest management, and the proposed solution is not an obstacle to other aspects of the company's operation.

\section{Step 3: Forming the research team and analytical workshop}

The formation of the solving team is focused on a comprehensive solution of the design details. Therefore, it is crucial to find out which employees can perform a specific task and join a given project. The introductory workshop is a follow-up step in which the persons concerned will meet the team leaders, the head of the logistics department, the company management and others [2]. In this workshop, it is necessary to say all the information that relates to the solution of the problem and especially such information that can be used in the Ceit Table software, e.g. routes of AGV trucks, workplace layout, product BOM, detailed information on the method of transport by trucks, etc.

\section{Step 4: Solving team}

Setting up a solving team is important and should be made up of members from different levels of the company who may be affected. In addition to members of the company and management, they are mainly: technologist's head of planning and purchasing, logistics department, operational planning. Masters and timers, who know best how production works, so it is necessary and beneficial to address and communicate between them, can advise many things.

\section{Step 5: Schedule and division of tasks}

In order to better understand the process of performing the tasks assigned to the responsible persons about the completion dates, the project needs to be divided into individual phases. When using the schedule, team members will be able to perform their tasks correctly, perform their work on time and responsibly. Another benefit of such a schedule is the elimination of possible mistakes in future meetings and support for creating new ideas. We can implement a schedule in the Gantt chart, for example.

\section{Step 6: Data collection}

It is necessary to know the accuracy of the obtained data because it is the basis for creating and designing a logistics model. If the data is correct, we can proceed to create a database of products and components. The procedure from which it begins and how the data collection and processing continues is shown in the algorithm in the figure (Figure 3). 


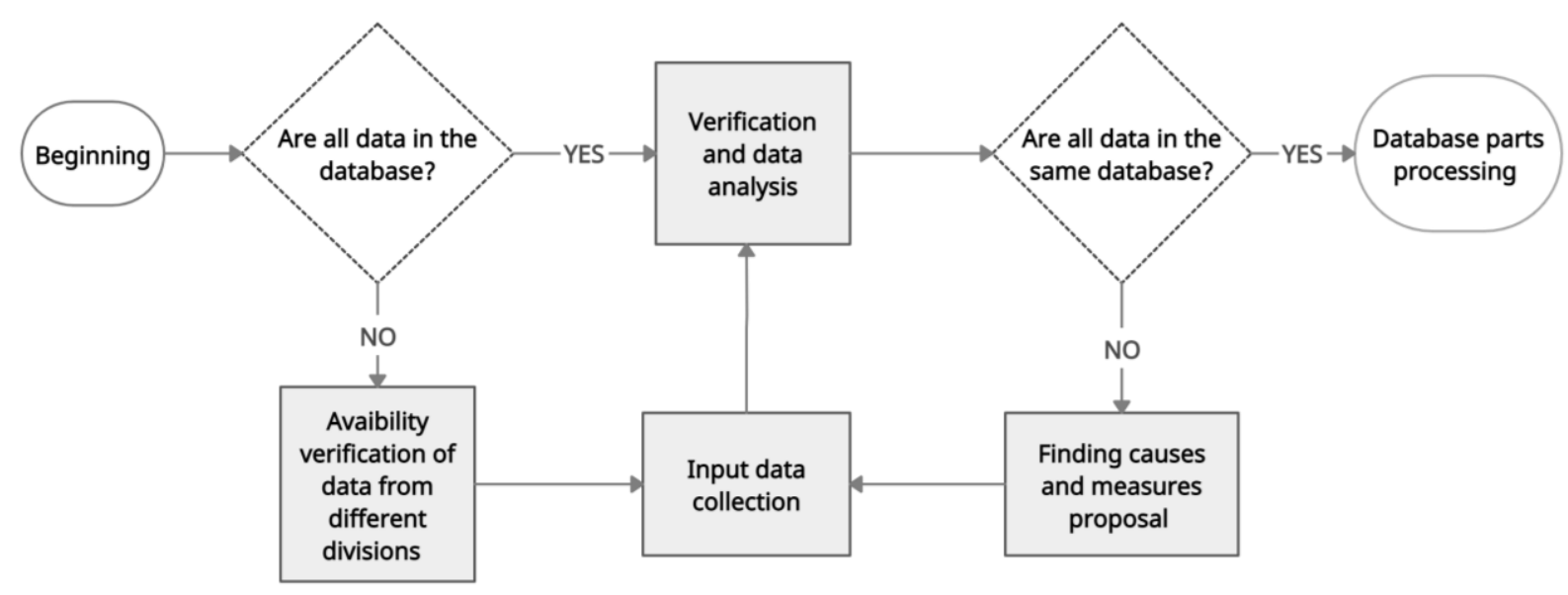

Figure 3-Data collection and processing algorithm

(Source: Bastiuchenko, Vsevolod)

\section{Step 7: Process analysis}

A detailed analysis of all logistics processes and flows in the entire company and directly within the production islands will allow us to design automated logistics [5]. The steps of the analysis procedure:

1. Find out the principle of functioning of the organizational structure of logistics.

2. Identify and verify the characteristics of the main transport relationships.

3. How and where to order, receive and store material.

4. Learn about the supply process of production islands and lines.

5. Learn about how to complement and pick parts.

6. Analysis of the production islands related to the project, and so on.

\section{Step 8: Summary of the analysis results}

This point must contain a description of the key findings during the analysis of the research object in the selected company. The volume of information should be structured to give the reader a picture of the system, especially the advantages and disadvantages. There may also be a visualisation of sections that have potential and need for improvement. The results of the analysis and its summary form the basis of the design itself.

\section{Step 9: Create a design using the CEIT Table software}

The envisaged design of automated logistics can only be created when all the necessary data have been collected, approved and described. With this in mind, it is possible to start planning and creating a project in the software. Steps of creation model in software Ceit Table: 
1. Creating a new project - For design purposes, the system allows generating logistic links for all types of handling equipment (human, tractor, etc.) and draw them through material, transport flows, capacity, and check or dimension them. Then these routes, twists, charging points are marked in the figures as, for example, T or R (Figure 4 and Figure 5). Therefore, it is necessary to obtain and set information to system modules in advance, e.g.:

- module for designing production systems in 2D / 3D environment,

- module for setting the basics of logistics (e.g. defining the number of handling units, defining inventory turnover in the warehouse or workplaces, capacity dimensioning of warehouse areas, import of data in XLS format, etc.),

- module for logistics system design (e.g. logistics network generation, material flow plotting as Sankey diagram, Spaghetti diagram, material flow analysis, etc.,

- module for planning and balancing operations (calculation of operator workload, Standardization of operations using the MTMUAS methodology, scheduling of operations by individual workplaces / such, etc.).

2. Import and customization of a real drawing - For example, importing 2D or 3D models of objects, machines, vehicles, buildings and so on.

3. Creating a virtual logistics map - All objects that are to be part of the logistics network are connected to this network.

4. Creation of transport flows - For example, settings of material flow behaviour, for which a checkerboard table setting can be used.

5. Adding handling tools - It is a tool ensuring the allocation of logistics activities to individual handling means.

6. Adding products - Setting the BOM of different products by for example part number.

7. Demonstration of results - For example, in the form of extensive graphs (Figure 1), visualization trough a 3D virtual map (Figure 4 and Figure 5), etc.

Examples of a finished automated logistics system in the Ceit Table software environment is shown on Figure 4 and Figure 5. 


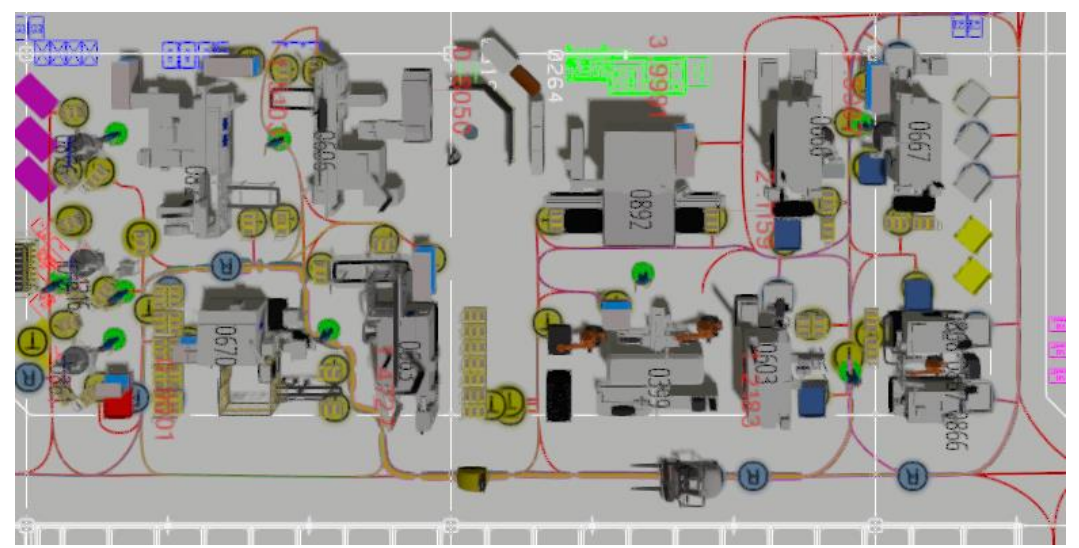

Figure 4-Example of 3D model created in software Ceit Table

(Source: Bastiuchenko, Vsevolod)

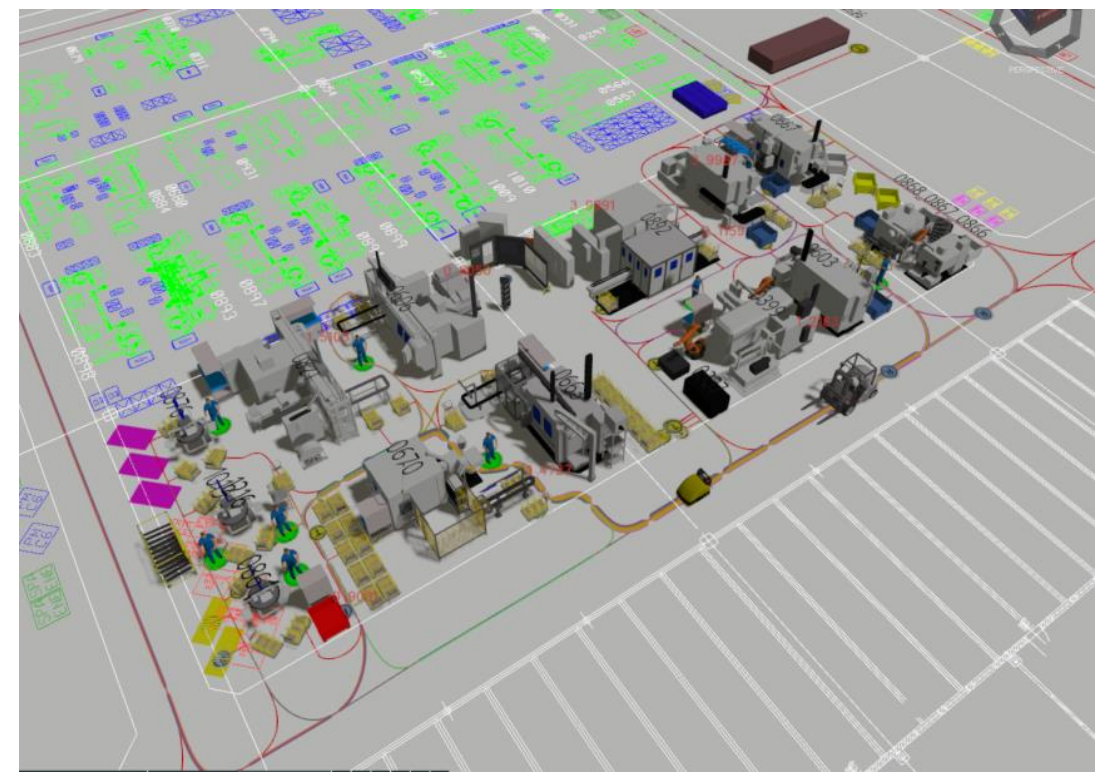

Figure 5-Example of 3D model created in software Ceit Table (Source: Bastiuchenko, Vsevolod)

\section{Conclusion}

Benefits of the system while working with a project in the CEIT Table software:

- The project is gradually filled with new data, which is displayed in the hierarchy's perspective. As a result, it is easy to find, edit and analyse each item, which allows us to present a complete picture of the current state.

- Thanks to the display window of the world in the software environment, it is possible to see and monitor not only statistical results but also a graphical representation of the final product of the work [3]. By entering the values correctly, the software can calculate the results and present 
them in a graphical display, thus saving time, as if it were calculated manually.

- In each project, the software allows the data to be modified, which means that several possible variants can be made. The way of adding new 3D models and their modification allows you to work with the visual side of the project. Finally, the virtual tour function directly in the software opens up the possibility of presenting the finished result to the customer [6].

The benefit of the presented methodology steps is that they can be understand as a basis for designing and implementing new projects in the areas of logistics, production and control systems. Side benefits, even under the conditions of successful implementation of an automated system, are for example elimination of human error increases safety when transporting pallets, increased accuracy of the amount of transported material, through electronic parts ordering, we get to an improved communication system between warehouse and production, and so on.

\section{Acknowledgments}

This article was created with support of project: KEGA 017ŽU-4/2019.

\section{Literature}

[1] ASSECO CEIT a.s. Ceit Table [online]. [cit. 2. 8. 2021]. Available from: https://www.asseco-ceit.com/sk/produkty/ceit-table/

[2] FUSKO, M., RAKYTA, DULINA, L'., SULÍROVÁ, I., EDL, M. Digitization in the technical service management system. MM Science Journal, March 2018. 2260-2266. ISSN 1803-1269.

[3] GREGOR M., HERČKO J., GRZNÁR P. The Factory of the Future Production System Research, In: 21st International Conference on Automation and Computing (Icac), 2015. ISBN 978-0-9926-8010-7.

[4] MIČIETA B., EDL M., KRAJČOVIČ M., DULINA L'., BUBENÍK P., ĎURICA L., BIŇASOVÁ V. Delegate MASs for coordination and control of onedirectional AGV systems: a proof-of-concept. In: The International journal of Advanced Manufacturing technology. 2018. 94, p. 415-431. ISSN 02683768.

[5] PLINTA D., KRAJČOVIČ M. Production system designing with the use of digital factory and augmented reality technologies. In: Progress in automation, robotics and measuring techniques: control and automation, Advances in intelligent systems and computing. 2015. 350, p. 187-196, ISSN 2194-5357. ISBN 978-3-319-15795-5.

[6] SVITEK, R. Návrh metodiky projektovania logistického systému v prostredí digitálneho dvojčat'a, Žilina, 2021. Dizertačná práca. Žilinská univerzita v Žiline, s. 128.

[7] TREBUŇA, P., PEKARČíKOVÁ, M., KLIMENT, M., TROJAN, J. Metódy a systémy riadenia výroby $v$ priemyselnom inžinierstve. Košice: Technická Univerzita v Košiciach, 2019, 210 s. ISBN 978-80-553-3280-2. 